\title{
PERMASALAHAN YANG TERJADI DI RUMAH SAKIT TERKAIT KESELAMATAN PASIEN
}

\author{
Christin Butar Butar
}

christinbutarbutar19@gmail.com

\section{Latar Belakang}

Rumah sakit sebagai instansi pelayanan kesehatan yang berhubungan langsung dengan pasien harus mengutamakan pelayanan kesehatan yang aman, bermutu, antidiskriminasi dan efektif dengan mengutamakan kepentingan pasien sesuai dengan standar pelayanan rumah sakit. Keselamatan pasien merupakan hak pasien, pasien berhak memperoleh keamanan dan keselamatan dirinya selama masa perawatan di rumah sakit. UU No 36/2009 Pasal 53 tentang kesehatan menyatakan bahwa pelaksanaan pelayanan kesehatan harus mendahulukan nyawa pasien. Keselamatan pasien telah menjadi prioritas untuk layanan kesehatan seluruh dunia.

Yang dimaksud dengan keselamatan pasien (patient safety) adalah proses dalam suatu Rumah Sakit yang memberikan pelayanan pasien yang lebih aman termasuk di dalamnya asesmen risiko, identifikasi, dan manajemen risiko terhadap pasien, pelaporan dan analisis insiden, kemampuan untuk belajar dan menindaklanjuti insiden, dan menerapkan solusi untuk mengurangi serta meminimalisir timbulnya risiko dimana rumah sakit membuat asuhan yang lebih aman melalui upaya-upaya, mengidentifikasi resiko, pengelolaan resiko, belajar dari resiko yang terjadi agar tidak terulang dimasa yang akan dating dengan lebih sederhana dapat dikatakan keselamatan pasien rumah sakit adalah mencegah kejadian yang tidak diinginkan, apabila tidak dapat dicegah diupayakan agar tidak terulang, melalui upaya belajar dari kesalahan.Keselamatan merupakan prinsip dasar dalam pelayanan pasien dan komponen kritis dari manajemen mutu. (WHO, 2004 dalam Lumenta, 2011).

Kementerian Kesehatan Republik Indonesia telah mengeluarkan Peraturan Menteri Kesehatan No. 11 Tahun 2017 tentang Keselamatan Pasien di Rumah Sakit. Peraturan ini menjadi tonggak utama operasionalisasi keselamatan pasien di rumah sakit seluruh Indonesia. Banyak rumah sakit di Indonesia yang telah berupaya membangun dan mengembangkan keselamatan pasien, namun upaya tersebut dilaksanakan berdasarkan pemahaman manajemen terhadap keselamatan pasien. Peraturan menteri ini memberikan panduan bagi manajemen rumah sakit agar dapat menjalankan spirit keselamatan pasien secara utuh.

Kata Kunci : Pasien Safety, Keselamatan Pasien, Rumah Sakit 


\section{Metode}

Permasalahan yang terjadi di rumah sakit terkait dengan keselamatan pasien menggunakan metode pengumpulan data dari berbagai sumber yang sudah terjamin datanya seperti melalui jurnal, textbook dan tesis dimana jurnal, textbook dan tesis dengan tahun 2012 hingga 2020. Pengambilan informasi melalui jurnal, textbook dan tesis adalah untuk mendapatkan berbagai informasi yang lengkap dan akurat

\section{Hasil}

Berdasarkan Permenkes Nomor 11 Tahun 2017 tentang Keselamatan Pasien, insiden keselamatan pasien dapat dibagi berdasarkan jenis insiden yang terdiri dari Kondisi Potensial Cedera (KPC), Kejadian Tidak Cidera (KTC), Kejadian Nyaris Cidera (KNC), Kejadian Tidak Diharapkan (KTD), dan Kejadian Sentinel. KNC merupakan terjadinya insiden yang belum terpapar pada pasien. KNC lebih sering terjadi dibandingkan dengan kejadian tidak diharapkan, frekuensi kejadian ini tujuh sampai seratus kali lebih sering terjadi. Data KNC harus dianalisis agar pencegahan dan pembentukan sistem dapat dibuat sehingga cedera aktual tidak terjadi. Pada sebagian besar kasus KNC memberi dampak pada pembuatan model penyebab dari insiden (incident causation model) atau proses hingga kejadian nyaris cedera terjadi Model penyebab terjadinya insiden, KNC berperan sebagai pelopor awal sebelum terjadinya KTD. Kejadian nyaris cedera menyediakan dua tipe informasi terkait dengan kamanan pasien yakni kelemahan dari sistem pelayanan kesehatan (kesalahan dan kegagalan termasuk tidak adekuatnya sistem pertahanan) dan kekuatan dari sistem pelyanan kesehatan (tidak ada perencanaan, tindakan pemulihan secara informal) 


\section{Pembahasan}

Keselamatan pasien (patient safety) adalah suatu sistem dimana rumah sakit membuat asuhan pasien lebih aman dalam upaya mencegah terjadinya cidera yang disebabkan oleh kesalahan akibat melaksanakan suatu tindakan atau tidak mengambil tindakan yang seharusnya diambil. Menurut Komite Keselamatan Pasien Rumah Sakit tahun 2008, keselamatan pasien adalah kondisi pasien bebas dari cedera yang tidak seharusnya terjadi yang masih bisa dihindari atau bebas dari risiko dan cidera yang berpotensial akan terjadi. Berdasarkan Peraturan Menteri Kesehatan Republik Indonesia Nomor 11 Tahun 2017, keselamatan pasien merupakan suatu sistem yang membuat asuhan pasien lebih aman, meliputi asesmen risiko, identifikasi dan pengelolaan risiko pada pasien, pelaporan dan analisis insiden, kemampuan belajar dari insiden dan tindak lanjutnya, serta implementasi solusi untuk meminimalkan timbulnya risiko dan juga mencegah terjadinya cidera yang disebabkan kesalahan akibat melaksanakan suatu tindakan atau tidak mengambil tindakan yang seharusnya diambil. Berdasarkan laporan KKPRS terdapat 144 insiden (2009), 103 insiden (2010), dan 34 laporan insiden pada triwulan I tahun 2011. Rendahnya insiden di Indonesia oleh karena tidak semua insiden terlaporkan. Umumnya insiden tidak dilaporkan, tidak dicatat, dan juga bahkan luput dari perhatian petugas kesehatan karena yang dilaporkan hanya insiden yang ditemukan secara kebetulan saja.4Beberapa faktor yang mempengaruhi rendahnya laporan insiden yaitu sebagai berikut:

1) Pelaporan insiden masih dipersepsikan sebagai pekerjaan perawat, seharusnya yang membuat laporan tersebut adalah siapa saja atau semua staf yang pertama menemukan kejadian dan yang terlibat dalam insiden,

2) Insiden yang terjadi sering disembunyikan (underreport), insiden dilaporkan namun sering terlambat serta laporan tersebut miskin data,

3) Masih adanya budaya menyalahkan (blame culture) menjadi penyebab terhambatnya pelaporan insiden karena takut disalahkan oleh manajemen dan unit terkait (adanya ketakutan petugas untuk melaporkan)

4) Kurangnya komitmen pimpinan,

5) Kurangnya sosialisasi dan pelatihan pelaporan IKP kepada semua pihak di organisasi, sehingga petugas tidak tahu apa dan bagaimana cara melaporkan ketika insiden terjadi. Pengetahuan memegang peranan penting dalam proses pelaporan IKP, apabila petugas sendiri tidak paham bagaimana sistem pelaporan IKP menyebabkan IKP tidak terlaporkan, 
6) Tidak ada reward dari rumah sakit jika melaporkan.

7) Tingginya beban kerja.4 Hal tersebut

menjadi tantangan semua pihak. Pemerintah dan fasilitas kesehatan bertanggung jawab memastikan sistem pelaporan dapat terlaksana dengan baik

Menurut PMK No. 11 Tahun 2017 tentang Keselamatan Pasien, Insiden keselamatan pasien adalah setiap kejadian yang tidak disengaja dan kondisi yang mengakibatkan atau berpotensi mengakibatkan cedera yang dapat dicegah pada pasien, terdiri dari kejadian tidak diharapkan, kejadian nyaris cedera, kejadian tidak cedera, dan kejadian potensial cedera. Adapun jenisjenis insiden yang ditetapkan dalam PMK No. 11 Tahun 2017 adalah sebagai berikut.

a. Kondisi Potensial Cedera (KPC) adalah kondisi yang sangat berpotensi untuk menimbulkan cedera, tetapi belum terjadi insiden. Contohnya obat-obatan LASA (look a like sound a like) disimpan berdekatan.

b. Kejadian Nyaris Cedera (KNC) adalah suatu kejadian insiden yang belum sampai terpapar ke pasien. Contohnya suatu obat dengan overdosis lethal akan diberikan kepada pasien, tetapi staf lain megetahui dan membatalkannya sebelum obat tersebut diberikan kepada pasien.

c. Kejadian Tidak Cedera (KTC) adalah suatu kejadian akibat melaksanakan suatu tindakan (comission) atau tidak mengambil tindakan yang seluruhnya diambil (omission) yang dapat mencederai pasien tetapi cedera tidak terjadi karena:

1) "keberuntungan" (misalnya pasien yang menerima suatu obat kontra indikasi tetapi tidak timbul reaksi obat); dan

2) "peringatan" (misalnya pasien secara tidak sengaja telah diberikan suatu obat dengan dosis lethal, segera dietahui secara di lalu diberikan antidotumnya sehingga tidak menimbulkan cedera berat).

d. Kejadian Tidak Diharapkan (KTD) adalah kejadian yang mengakibatkan cedera pada pasien akibat melaksanakan suatu tindakan (comission) atau tidak mengambil tindakan (omission) dan bukan karena penyakit dasarnya (underlying disease) atau kondisi pasien. Cedera dapat diakibatkan oleh kesalahan medis atau bukan kesalahan medis. Contoh KTD 
yaitu pasien yang diberikan obat A dengan dosis lebih kareba kesalahan saat membaca dosis obat pada resep sehingga pasien mengeluhkan efek samping dari obat tersebut.

e. Kejadian Sentinel adalah suatu KTD yang mengakibatkan kematian, cedera permanen, atau cedera berat yang temporer dan membutuhkan intervensi untuk memperthankan kehidupan, baik fisik maupun psikis, yang tidak terkait dengan perjalanan penyakit atau keadaan pasien. Kejadian sentinel biasanya dipakai untuk kejadian tidak diharapkan atau tidak dapat diterima seperti operasi pada bagian tubuh yang salah. Pemilihan kata sentinel terkait dengan keseriusan cedera yang terjadi misalnya amputasi pada lokasi yang salah, dll, sehingga pencarian fakta-fakta terhadap kejadian ini mengungkapkan adanya masalah yang serius pada kebijakan dan prosedur yang berlaku.

WHO juga mengingatkan bahwa "keselamatan pasien tidak hanya tentang data statistik tetapi melibatkan kerusakan yang nyata pada kehidupan orang-orang". Oleh karenanya semua strategi dan program keselamatan pasien harus menjadi prioritas dalam pelayanan kesehatan. Pasien, professional kesehatan dan pembuat kebijakan semua harus bekerja sama untuk membangun sistem kesehatan yang lebih aman.Menurut National Health Performance Committee (NHPC, 2001, dikutip dari Australian Institute Health and Welfare (AIHW, 2009) mendefinisikan keselamatan pasien adalah menghindari atau mengurangi hingga ketingkat yang dapat diterima dari bahaya aktual atau risiko dari pelayanan kesehatan atau lingkungan di mana pelayanan kesehatan diberikan. Fokus dari definisi ini adalah untuk mencegah hasil pelayanan kesehatan yang merugikan pasien atau yang tidak diinginkan. Institute of Medicine (2000) mendefinisikan keselamatan pasien adalah "freedom from accidental injury".

Sedangkan Kelley dan Hurst (2006, dikutip dari AIHW, 2009) mendefinisikan keselamatan pasien adalah tingkat dimana menghindari, mencegah, dan memperbaiki hasil atau cedera yang merugikan dari proses pelayanan kesehatan. Elder dan Dovey (2002), membuat sistem klasifikasi kesalahan dalam pelayanan kesehatan yang seharusnya dapat dicegah terkait dengan pelayanan primer dan kesalahan dalam proses, adalah;

1. Klasifikasi kesalahan pada pelayanan primer, meliputi;

a. Terkait dengan diagnosis salah mendiagnosis dan tertunda mendiagnosis.

b. Pengobatan; salah obat, salah dosis, tertunda administrasi, tanpa administrasi, sedangkan non-obat; ketidaktepatan, terlambat, dihilangkan, komplikasi.

c. Pelayanan pencegahan ;terlambat, ditiadakan, komplikasi. 
2. Klasifikasi kesalahan pada proses:

a. Faktor dokter; kesalahan penilaian klinis, kesalahan prosedur keterampilan,

b. Faktor perawat; kesalahan komunikasi dan kesalahan prosedur keterampilan,

c. Kesalahan komunikasi; dokter-pasien, dokter-dokter atau sistem dan personil pelayanan kesehatan lainnya,

d. Faktor administrasi; dokter, farmasi, perawat, terapi fisik, terapi pekerjaan, pengaturan kantor.

e. Faktor akhir; pribadi dan masalah keluarga, dokter, perawat dan staf, peraturan perusahaan asuransi, peraturan pemerintah, pembiayaan, fasilitas dan lokasi praktek, dan sistem umum pelayanan kesehatan.

Masalah keselamatan pasien dari berbagai jenis terjadi selama pelayanan kesehatan berlangsung. Termasuk kesalahan transfusi dan efek samping obat, salah operasi dan luka bedah, pengendalian terkait cedera atau kematian, infeksi terkait perawatan rumah sakit, jatuh, luka bakar, ulkus decubitus, dan kesalahan identitas pasien. Leape, Lucian, Lawthers, Brennan, Troyen (1993 dikutip dari IOM, 2000) menyebutkan ciri jenis kesalahan yang mengakibatkan cedera;

1) Diagnostik; kesalahan atau keterlambatan diagnosis, kegagalan untuk menggunakan hasil dari tes diagnostik, menggunaan tes diagnostik atau terapi yang sudah ketinggalan zaman, kegagalan untuk bertindak berdasarkan hasil pemantauan atau pengujian.

2) Pengobatan; kesalahan dalam pelaksanaan operasi, prosedur, atau uji, kesalahan dalam mengelola perawatan, kesalahan dalam dosis atau metode menggunakan obat, keterlambatan dalam pengobatan atau dalam menanggapi tes abnormal, dan tidak menunjukan kepedulian.

3) Pencegahan; kegagalan untuk memberikan perawatan profilaksis, pemantauan yang tidak memadai atau tindak melanjutkan pengobatan.

4) Lain-lain; kegagalan komunikasi, kegagalan peralatan, kegagalan sistem 


\section{Kesalahan obat}

Memastikan penggunaan obat yang sesuai merupakan proses yang kompleks melibatkan beberapa organisasi dan para profesional dari berbagai disiplin ilmu, misalnya; pengetahuan obat, akses yang tepat terhadap informasi obat, pasien yang akurat, dosis yang tepat, cara yang benar, kegagalan untuk memberikan obat yang diresepkan dan serangkaian keputusan yang saling terkait selama periode waktu pengobatan. Pasien juga membuat kesalahan dalam masalah obat, khususnya pada pasien atau masyarakat yang mengalami perawatan jangka panjang, dan mengalami ketergantungan lebih besar pada terapi obat yang kompleks. Kesalahan obat sering dapat dicegah, meskipun untuk mengurangi kesalahan pada tingkat yang signifikan memerlukan beberapa intervensi.

WHO pada tanggal 2 Mei 2007 menerbitkan panduan “ Nine life-saving patient safety solution" Sembilan solusi keselamatan pasien rumah sakit :

1. Perhatikan Nama Obat, Rupa dan Ucapan Mirip ( Look-Alike, Sound- Alike Medication Names)

2. Pastikan Identifikasi Pasien

3. Komunikasi Secara Benar saat serah terima/pengoperan pasien

4. Pastikan tindakan yang benar pada sisi tubuh yang benar

5. Kendalikan cairan elektrolit pekat (concentrated)

6. Pastikan akurasi pemberian obat pada pengalihan pelayanan

7. Hindari salah kateter dan salah sambung slang (tube)

8. Gunakan alat injeksi sekali pakai

9. Tingkatkan kebersihan tangan (Hand hygiene) untuk pencegahan infeksi nasokomial Berdasarkan UU No.1691/MENKES/PER/VIII/2011 tentang patient safety pihak rumah sakit diharuskan melakukan kegiatan pelayanan dengan lebih mengutamakan patient safety. Kurangnya kesadaran dan kepedulian akan pentingnya patient safety akan mengakibatkan kerugian bagi pihak rumah sakit dan juga pasien seperti bertambah lamanya pasien dirawat yang akan berdampak pada semakin besarnya biaya yang harus ditanggung dan terjadinya resistensi obat. 


\section{Penutup}

Keselamatan pasien di Rumah sakit merupakan unsur penting guna meningkatkan kualitas pelayanan kesehatan khususnya di Rumah sakit sebagai bentuk implementasi dan refleksi sentuhan hasil kompetensi tenaga kesehatan, ketersediaan sarana dan prasarana layanan serta sistem manajeman dan administrasi dalam siklus pelayanan terhadap pasien. Permasalahan terkait keselamatan pasien dan proses mengatasi kejadian permasalahan keselamatan pasien di Rumah sakit sangat penting untuk dibahas. Karena ini akan menambaha wawasan serta untuk mengurangi angka kejadian terjadinya kelalaian terkait keselamatan pasien. Hal ini penting karena keselamatan pasien adalah suatu tanggung jawab dari pelayanan kesehatan terutama pada seorang perawat. Ada enam sasaran keselamatan pasien di rumah sakit yaitu ketepatan identifikasi, peningkatan komunikasi efektif, peningkatan keamanan obat yang perlu diwaspadai, kepastian tepat lokasi, tepat prosedur, tepat pasien operasi, pengurangan resiko infeksi terkait pelayanann kesehatan pengurangan resiko pasien jatuh. Keenam aspek tersebut sangat penting untuk dilaksanakan di setiap rumah sakit oleh karena itu diperlukan komitmen dan ethis dalam keperawatan. 


\section{Daftar Pustaka}

Aura Azzughira Salsabila, Stefanus Supriyanto. (2019). Analisis Insiden Kejadian Nyaris Cedera dan Kejadian Tidak Diharapkan di Rumah Sakit. Journal Kesehatan Masyarakat Aceh, vol 2 (3),20-30

Hajjul Kamil. (2016). Patient Safety. Idea Nursing Journal, vol 1(1)

Lita Salawati. (2020). Analisis Penerapan Manajemen Pasien Safety Dalam Rangka Peningkatan Mutu Pelayanan Kesehatan di Rumah Sakit. Jurnal Ners dan Kebidanan Indonesia, vol 5(2), 91-99

Muh Ryman Napirah, Lusia Salmawati, Andi Rahi (2019). Evaluasi Kebijakan Keselamatan Pasien (Pasien Safety) Pada Perawat di Rumah Sakit Umum Anutapura Kota Palu. Jurnal Kesehatan Masyarakat, vol 10(2), 65-72

Nanda Hani Juniati, Ahmad Ahid Mudayana. (2018). Penerapan Standar Keselamatan Pasien di Rumah Sakit Umum Daerah Provinsi Nusa Tenggara Barat. Jurnal Kesehatan Poltekkes Ternate, 11(2), 93-108

Simamora, R. H., \& Nurmaini, C. T. S. (2019). Knowledge of Nurses about Prevention of Patient Fall Risk in Inpatient Room of Private Hospital in Medan. Indian Journal of Public Health Research \& Development, 10(10), 759-763.

Sumarnio. (2017). Analisis Implementasi Patient Safety Terkait Peningkatan Mutu Pelayanan Kesehatan Kesehatan di Rumah Sakit. Jurnal Ners dan Kebidanan Indonesia, Vol 5(2), 91-99 Tria Harsiwi Nurul Insani, Sri Sundari. (2018). Analisis Pelaksanaan Keselamatan Pasien Oleh Perawat. Journal of Health Studies. Vol 2(1), 84-95

Tri Puji Astuti (2013). Analisis Penerapan Manajemen Pasien Safety Dalam Rangka Peningkatan Mutu Pelayanan di Rumah Sakit PKU Muhammadiyah Sukarta. Universitas Muhammadiyah Sukarta

Tutiany, Lindawati, Paula Krisanti. 2017. Manajemen Keselamatan Pasien. Jakarta : Kementerian Kesehatan Republik Indonesia

Yasmin Yulia, Hasbullah Thabrany. (2015). Faktor - Faktor Yang Berhubungan Dengan Budaya Keselamatan Pasien di Rumah Sakit Karya Bhakti Pratiwigo Bogor. Jurnal ARSI, Vol 4(2) 